\title{
CONTRIBUIÇÃO DA PRECIPITAÇÃO INTERNA PARA O APORTE DE NUTRIENTES EM ESTÁGIOS SUCESSIONAIS DA FLORESTA ATLÂNTICA NO PARANÁ
}

\author{
Renato Marques ${ }^{1 *}$, Geferson Elias Piazza ${ }^{2}$, Hilbert Blum ${ }^{1}$, Carolina Benghi Pinto ${ }^{3}$, Jonas
} Eduardo Bianchin ${ }^{4}$, Cilmar Antônio Dalmaso ${ }^{4}, K_{\text {Kauana Melissa Cunha Dickow }}^{5}$

\footnotetext{
1 *Doutor em Engenharia Florestal; Departamento de Solos e Engenharia Agrícola; Universidade Federal do Paraná; e-mail: rmarques@ufpr.br, hilbertblum@gmail.com

${ }^{2}$ Doutorando em Agroecossistemas; Universidade Federal de Santa Catarina; e-mail: gefersonpiazza@ yahoo.com.br ${ }^{3}$ Mestre em Engenharia Florestal; Universidade Federal do Paraná; e-mail: carolbenghi@gmail.com ${ }^{4}$ Doutorando em Engenharia Florestal; Universidade Federal do Paraná; e-mail: jonasbianchin@ gmail.com, cilmard@gmail.com

${ }^{5}$ Doutor em Engenharia Florestal; Laboratório de Análises de Solos; Universidade do Contestado; e-mail: kauanadickow@gmail.com
}

RESUMO: Este trabalho teve como objetivo avaliar a contribuição da precipitação interna para a entrada de nutrientes minerais em diferentes estágios sucessionais da Floresta Ombrófila Densa Submontana em Antonina, PR. As coletas de precipitação interna foram realizadas a cada três semanas, por meio de coletores tipo calha, distribuídos aleatoriamente nos três estágios sucessionais. Amostras de água foram coletadas para determinação do $\mathrm{pH}$ e dos íons $\mathrm{K}^{+}, \mathrm{Ca}^{2+}, \mathrm{Mg}^{2+}$ e $\mathrm{Na}^{+}$presentes na solução de precipitação interna. $\mathrm{O} \mathrm{pH}$ variou entre $6,11 \mathrm{e}$ 6,84 , sem diferença entre as fases sucessionais, mas com valores mais elevados no verão em comparação às demais estações do ano. A concentração dos íons em solução mostrou-se mais elevada nos períodos de menor precipitação (outono e inverno) e mais baixa nos períodos de maior precipitação (primavera e verão), caracterizando o efeito de diluição da concentração já identificado em outros estudos. Os íons em solução apresentaram a seguinte ordem decrescente de concentração: $\mathrm{K}^{+}>\mathrm{Na}^{+}>\mathrm{Ca}^{2+}>\mathrm{Mg}^{2+}$, sendo sua origem associada aos aerossóis marinhos. $\mathrm{O}$ aporte de nutrientes na precipitação interna seguiu esta mesma ordem, com maior aporte de $\mathrm{K}^{+}$ e $\mathrm{Ca}^{+2}$ no estágio avançado. Assim, a precipitação interna mostra-se uma importante via de transferência de nutrientes ao solo florestal.

Palavras-chave: Floresta Ombrófila Densa Submontana; florestas secundárias; hidrologia florestal; ciclagem de nutrientes.

\section{INTERNAL PRECIPITATION CONTRIBUTION TO THE INPUT OF NUTRIENTS IN SUCCESSIONAL STAGES OF ATLANTIC FOREST IN PARANÁ}

ABSTRACT: The aim of this work was to evaluate the nutrient input to the ecosystem by
throughfall on different areas of secondary forests in the Submontane Atlantic Rainforest in
Antonina, PR. Throughfall samples were taken every 3 weeks by gutters collectors, randomly
distributed in three sucessional stages. Water samples were collected to determine the pH and 
the ions of $\mathrm{K}^{+}, \mathrm{Ca}^{2+}, \mathrm{Mg}^{2+}$ and $\mathrm{Na}^{+}$in throughfall solutions. The values of $\mathrm{pH}$ varied between 6.11 and 6.84, without difference between sucessional stages, but with the highest values in summer compared to other seasons. The ions concentration in throughfall was higher on the dry season (autumn and winter) and lower on the wet season (spring and summer), showing the dilution/concentration effect already identified in other studies. The following concentration descending order was observed: $\mathrm{K}^{+}>\mathrm{Na}^{+}>\mathrm{Ca}^{2+}>\mathrm{Mg}^{2+}$. Ions origin was associated to marine aerosols. The input of nutrients by throughfall followed the same trend, with a highest input of $\mathrm{K}^{+}$and $\mathrm{Ca}^{+2}$ in the advanced stage. Therefore, throughfall can be considered an important way for the transfer of nutrients to the soil in the forests.

Key-words: Submontane Atlantic Rain Forest; secondary forests; forest hidrology; nutrient cycling.

\section{INTRODUÇÃO}

Nos ecossistemas florestais, a entrada de nutrientes pode ocorrer via precipitação úmida (chuvas, neve, neblina, p.e.), pela deposição de aerossóis ou poeiras carreados pelos ventos, pelo intemperismo da rocha matriz do solo, ou ainda pela fixação biológica do nitrogênio e pela fertilização artificial (GOLLEY et al., 1978, MILLER, 1984).

Na Floresta Atlântica do litoral do Paraná, devido às baixas reservas minerais nos solos (MINEROPAR, 2001), a entrada de nutrientes pelas águas da chuva pode ser uma importante fonte de manutenção da sustentabilidade florestal, que é garantida pela ciclagem de nutrientes via deposição/decomposição da serapilheira (BRITEZ, 1994; PINTO; MARQUES, 2003, DICKOW et al., 2012; BIANCHIN, 2013; WOICIECHOWSKI, 2015).

A cobertura vegetal nos ecossistemas florestais possui função de destaque no balanço hídrico, sendo que a entrada de água e nutrientes é influenciada pelo tipo da vegetação (DINIZ et al., 2013). As copas das árvores são responsáveis pelo primeiro fracionamento da água da chuva, onde uma parte fica temporariamente retida e evapora e outra parte atravessa a copa como gotejamento ou precipitação interna e como escoamento pelo tronco (ARCOVA et al., 2003). Neste processo, pode ocorrer o enriquecimento da solução com nutrientes, pela lavagem/lixiviação dos elementos presentes no dossel florestal ou, no sentido inverso, a captura de nutrientes pela vegetação por meio da absorção foliar (MARQUES; RANGER, 1997).

São raros os trabalhos no Brasil estudando a contribuição das águas da chuva e da precipitação interna para a entrada de nutrientes nos ecossistemas florestais, especialmente aqueles comparando a adição de nutrientes para áreas em diferentes estádios de regeneração 
(DINIZ et al., 2013). Em áreas de Floresta Atlântica destacam-se os trabalhos de Arcova e Cicco (1987), Britez (1994), Cintra (2004), Protil (2006), Souza et al. (2007), Scheer (2009) e Souza e Marques (2010), o que indica um número limitado de trabalhos, que não contemplam toda a diversidade de formações vegetais existentes nesse bioma.

Neste contexto, este trabalho buscou avaliar a contribuição da precipitação interna para o aporte de nutrientes minerais em diferentes estágios sucessionais de Floresta Ombrófila Densa Submontana, no litoral do Paraná, de forma a se compreender um pouco mais sobre o funcionamento biogeoquímico destas florestas.

\section{MATERIAIS E MÉTODOS}

\section{1 ÁREA DE ESTUDO}

O estudo foi realizado na Reserva Natural Rio Cachoeira (RNRC), situada na porção

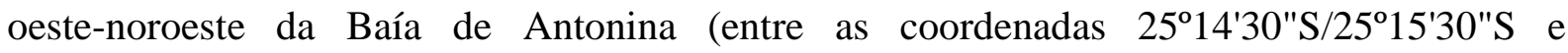
48³9'00"W/ 48³7'00"W), no município de Antonina, região litorânea do Estado do Paraná. A reserva pertence à ONG Sociedade de Pesquisa em Vida Selvagem e Educação Ambiental (SPVS).

A vegetação da área de estudo é classificada como Floresta Ombrófila Densa Submontana, situada entre 30 e 400 metros de altitude, aproximadamente (IBGE, 2012). As fases sucessionais do presente estudo foram descritas por Liebsch et al. (2007). A fase inicial (INI) é uma formação pioneira, abandonada há aproximadamente 20 anos, após utilização para pastagem. A densidade de indivíduos arbóreos é de 1890 ind ha ${ }^{-1}$, dos quais $66 \%$ correspondem a uma espécie predominante, a Tibouchina pulchra (Cham.) Cogn. (jacatirão); a riqueza foi de nove espécies (em $1000 \mathrm{~m}^{2}$ ) e a área basal de 21,5 $\mathrm{m}^{2} \mathrm{ha}^{-1}$. A fase média (MED) é uma formação intermediária, abandonada há aproximadamente 80 anos, após utilização para cultivo da mandioca. A densidade de indivíduos arbóreos é de 3006 ind ha ${ }^{-1}$; a riqueza foi de 63 espécies arbóreas (em $1500 \mathrm{~m}^{2}$ ) e a área basal de $34,8 \mathrm{~m}^{2} \mathrm{ha}^{-1}$. A floresta onde se situa a fase avançada (AVA) sofreu a retirada de madeira com valor comercial há aproximadamente 120 anos. A densidade de indivíduos arbóreos é de 1600 ind ha $^{-1}$; a riqueza encontrada foi de 56 espécies arbóreas (em $1500 \mathrm{~m}^{2}$ ) e a área basal de $40,1 \mathrm{~m}^{2} \mathrm{ha}^{-1}$. 
A região apresenta, de acordo com a classificação de Köppen e Geiger, o tipo climático subtropical úmido mesotérmico (Cfa), com a temperatura média do mês mais frio inferior a $18^{\circ} \mathrm{C}$, porém superior a $-3^{\circ} \mathrm{C}$, e o mais quente apresentando temperatura média superior a 22 ${ }^{\circ} \mathrm{C}$. As precipitações nas encostas atingem valores entre 3300 a $3450 \mathrm{~mm}$ anuais, abastecendo uma rede fluvial que desempenha um papel fundamental no sistema de drenagem da planície (MAACK, 2002). De acordo com dados meteorológicos dos últimos 15 anos, a temperatura média em Antonina é de $21,06{ }^{\circ} \mathrm{C}$ e as precipitações apresentaram média de $2.137 \mathrm{~mm}$, o que representa um valor de aproximadamente $65 \%$ da precipitação nas encostas (MAACK, 2002). As encostas da Serra do Mar constituem uma barreira aos ventos alísios de sudeste, constantes na direção do oceano para o continente, que originam chuvas orográficas e densos nevoeiros (Moraes, 1993), o que ocasiona maior precipitação nessas áreas. O mês mais seco é agosto, com $99,74 \mathrm{~mm}$ e janeiro o mais chuvoso com 437,23 mm. O mês mais quente do ano com média de $24,92{ }^{\circ} \mathrm{C}$ é fevereiro, enquanto o mês mais frio do ano é julho, com média de $16,99{ }^{\circ} \mathrm{C}$ (SIMEPAR, 2015). No ano de 2006, a variação da precipitação e da temperatura média seguiu o padrão mostrado na Figura 1.

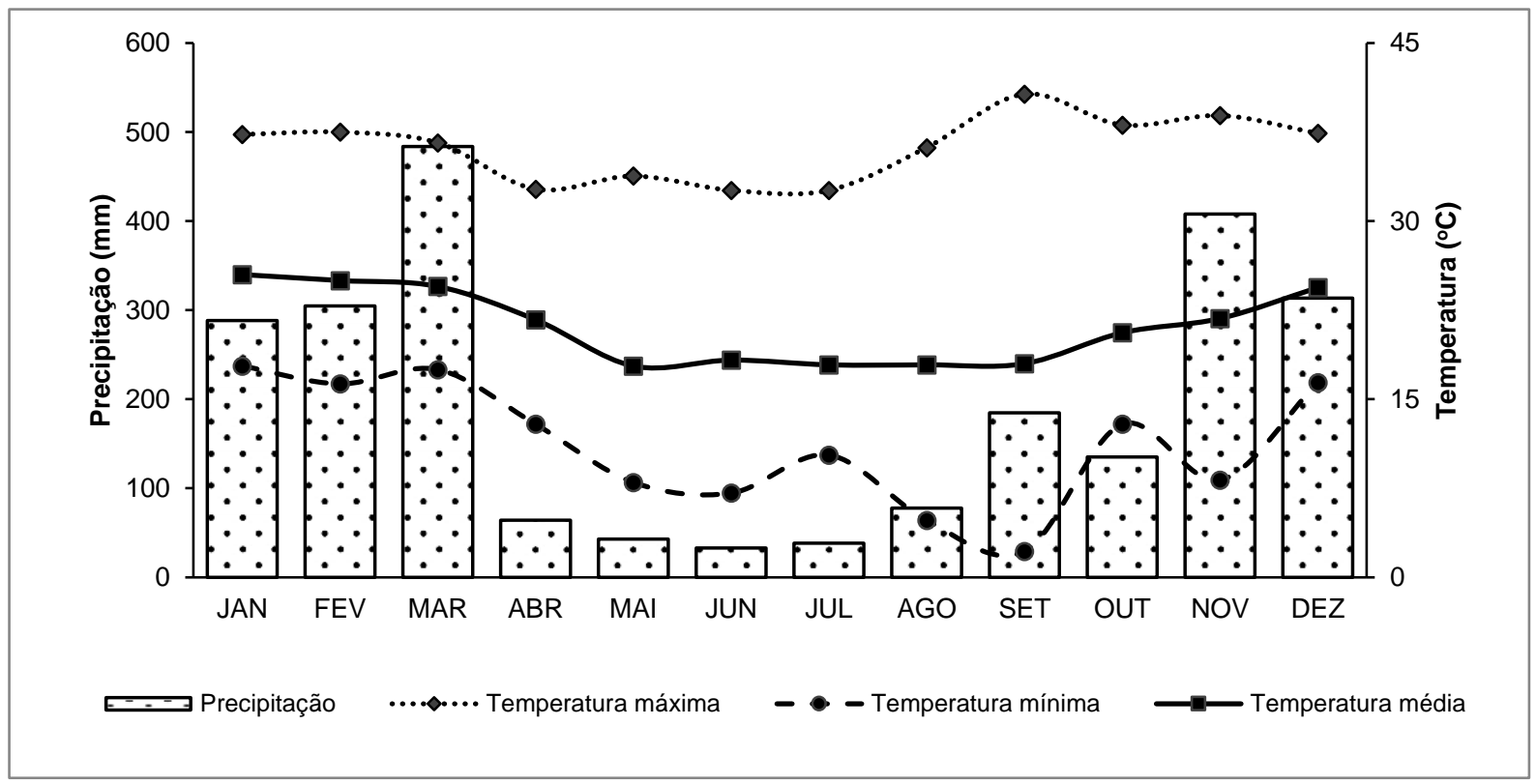

Figura 1. Dados meteorológicos de precipitação e temperatura da estação meteorológica do SIMEPAR em Antonina - PR, referente ao ano de 2006.

Figure 1. Meteorological data for precipitation and temperature from SIMEPAR weather station in Antonina - PR, 2006. 


\subsection{COLETA E QUANTIFICAÇÃO DE PRECIPITAÇÃO}

A precipitação efetiva que chega ao solo é composta pela precipitação interna somada ao escoamento pelo tronco (LIMA, 1975). Conforme já observado em trabalho anterior na Floresta Atlântica (SOUZA; MARQUES, 2010) e também neste trabalho, por ocasião de observações de campo em dias de chuva, não foi identificado fluxo de escoamento sobre o tronco, provavelmente devido à presença de epífitas no dossel das árvores, sobretudo nas florestas mais velhas.

A precipitação interna foi coletada, a cada três semanas, entre janeiro e dezembro de 2006. O dispositivo de coleta consistia de 5 coletores em forma de calha, instalados em cada uma das parcelas representando as fases sucessionais. Os coletores mediam 1,5 m x 0,12 m $\left(0,18 \mathrm{~m}^{2}\right)$, e foram conectados por uma mangueira a um tambor reservatório, que armazenava a água coletada (Figura 2).

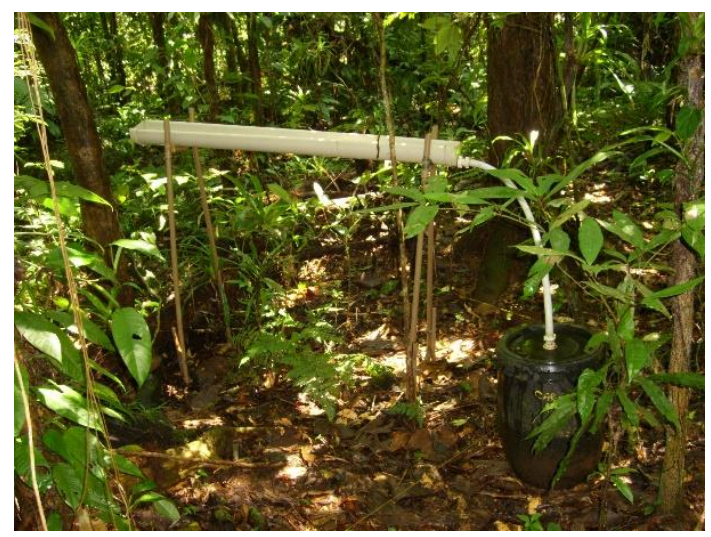

Figura 2. Coletor de precipitação no interior da floresta, em Antonina, PR.

Figure 2. Throughfall collector in the forest in Antonina, PR.

No campo, o volume precipitado foi medido com auxílio de uma régua graduada em centímetros, com a qual se media a altura da lâmina d'água no tambor $(h)$. Este procedimento, adotado por Souza e Marques (2010), facilita a coleta de dados no campo, sobretudo quando os tambores apresentam uma grande quantidade de água. A conversão da altura de lâmina d'água em volume é possível graças a uma calibração prévia que leva em conta a forma não cilíndrica do tambor de armazenamento. Assim, para a estimativa do volume de precipitação, foi levada em consideração a altura da lâmina d'água no tambor $(h)$, a superfície de coleta das calhas $(0,18$ 
$\mathrm{m}^{2}$ ) e fatores de conversão que permitiram a obtenção do volume (L) e sua transformação em lâmina de chuva (mm), conforme equação abaixo:

$$
P I=\frac{(1,233939 \times h)-0,846667}{A C}
$$

Onde: PI = Precipitação interna $(\mathrm{mm}) ; \mathrm{h}=$ altura da lâmina d'água no tambor $(\mathrm{cm}) ; \mathrm{AC}=$ área do coletor $\left(\mathrm{m}^{2}\right)$.

Após medição da altura da lâmina d'água, uma amostra de cerca de $125 \mathrm{ml}$ da solução foi coletada de dentro do tambor, para posteriores análises químicas e determinação do $\mathrm{pH}$.

\subsection{ANÁLISES QUÍMICAS}

Após o processo de coleta a campo, as 45 amostras (a cada três semanas) foram imediatamente armazenadas em geladeira no Laboratório de Biogeoquímica (LAB) no Departamento de Solos e Engenharia Agrícola da UFPR, para análise do pH e da concentração de nutrientes minerais nas soluções de PI. As amostras foram filtradas somente para eliminar partículas mais grosseiras. O pH foi determinado em pHmetro WTW 340i. As concentrações de $\mathrm{K}^{+}$e $\mathrm{Na}^{+}$foram determinadas por emissão em fotômetro de chama Digimed-NK2000. Os

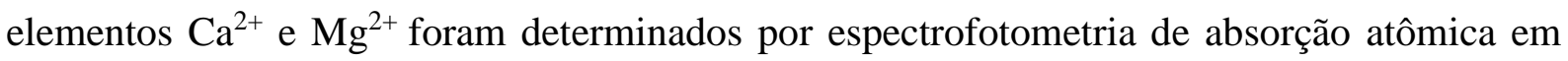
espectrofotômetro Shimadzu AA-6200.

A não determinação do íon fosfato se deve ao fato da concentração de $\mathrm{P}$ ser geralmente baixa na água da chuva, o que faz com que este elemento não tenha sido determinado nos poucos trabalhos sobre composição da chuva existentes para a região da Floresta Atlântica (FORTI et al., 2005; SOUZA et al. 2006). Na precipitação interna, estes valores podem ser ainda mais baixos, devido à absorção deste elemento via foliar (MARQUES et al., 1997). Outros íons como nitrato, amônio, sulfato e cloreto, que seriam de interesse da pesquisa, não puderam ser determinados por carência instrumental do laboratório na ocasião deste trabalho. 


\subsection{ANÁLISES ESTATÍSTICAS}

Para comparar os valores de precipitação interna, $\mathrm{pH}$, concentração e aporte de nutrientes da solução nos diferentes estágios sucessionais e estações climáticas, foi realizado o teste de Kruskal-Wallis com comparações múltiplas para $\mathrm{p}<0,05$. As análises foram realizadas com software de estatística Action $®$ integrado ao Excel (EQUIPE ESTATCAMP, 2014).

\section{RESULTADOS E DISCUSSÃO}

\subsection{PRECIPITAÇÃO INTERNA NA FLORESTA}

A precipitação interna atingiu uma quantidade total de $2262 \mathrm{~mm}$ na área em estágio inicial de regeneração, $2155 \mathrm{~mm}$ na área em estágio médio e $2239 \mathrm{~mm}$ na área em estágio avançado (Figura 3). Pelo teste de comparações múltiplas, a precipitação interna foi inferior no outono e inverno comparativamente aos valores na primavera e verão, porém não diferiu entre os estágios sucessionais. Diniz et al. (2013) encontraram valores de precipitação incidente, precipitação efetiva e de interceptação similares entre os estágios sucessionais em um remanescente de Floresta Atlântica em Pinheiral, RJ. Outros trabalhos realizados encontraram valores de precipitação interna maiores no estágio inicial em relação ao estágio avançado (LORENZON et al., 2013). Backes (2007) cita que a interceptação pelo dossel varia em função da heterogeneidade da estrutura florestal, da diversidade das espécies arbóreas, do tamanho e forma das copas e pela forma e intensidade da chuva. Geralmente os estágios iniciais, como ocorrem nas parcelas deste estudo, possuem árvores mais baixas, menor densidade populacional e menor área basal do que os estágios médio e avançado. Se a estrutura da vegetação é menos complexa na fase inicial, à medida que a sucessão evolui, a vegetação fica mais densa, apresentando um dossel e área basal mais desenvolvidos, o que vem a contribuir para uma maior interceptação da precipitação pela vegetação das fases média e avançada. Apesar de a precipitação interna ter sido maior no estágio avançado no outono e inverno, comparado aos outros estágios, elas não diferiram estatisticamente entre si. 


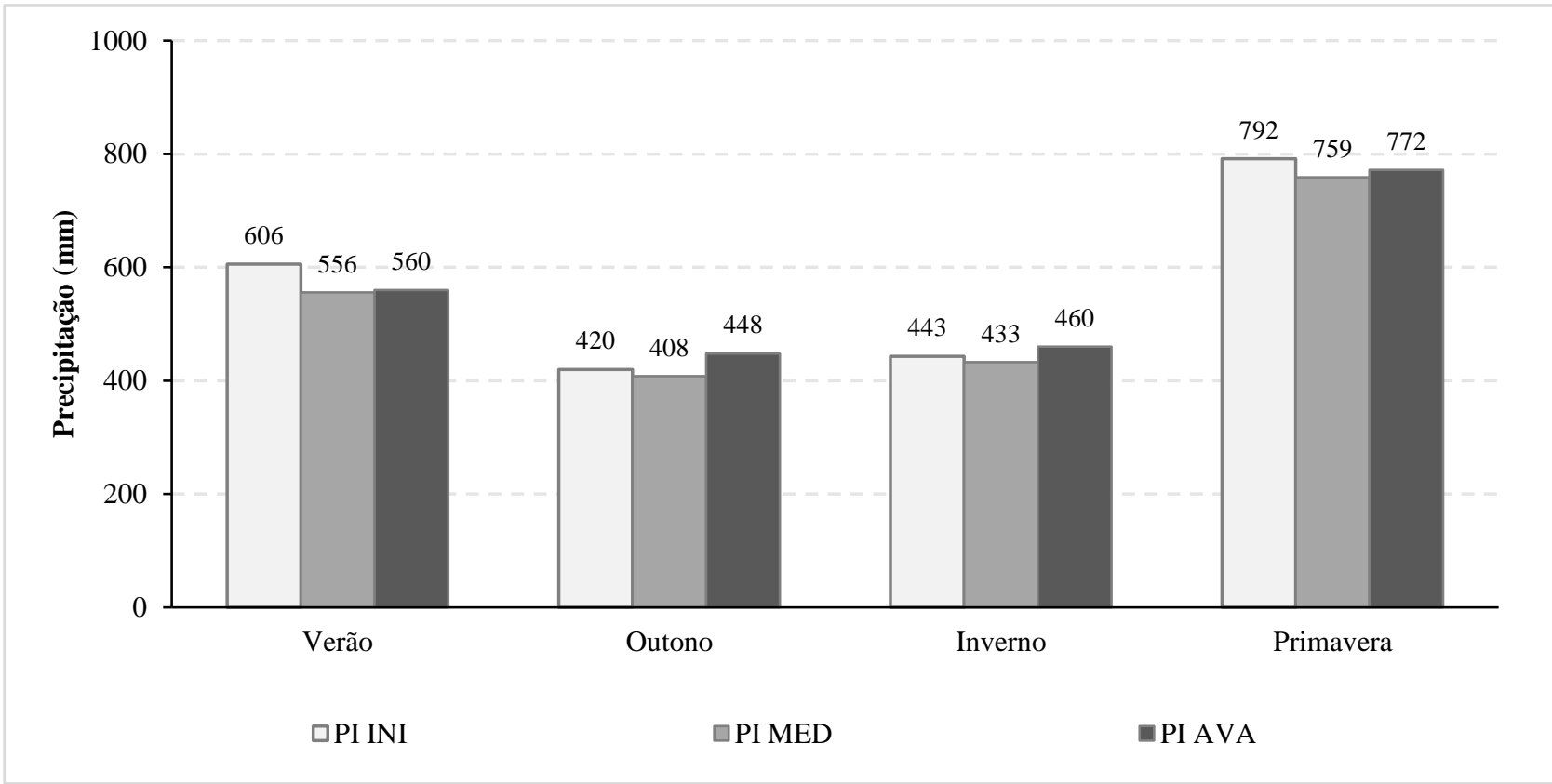

Figura 3. Precipitação interna (PI) por estação do ano e estágio sucessional (inicial - INI, médio - MED e avançado - AVA) em Floresta Ombrófila Densa Submontana em Antonina, PR.

Figure 3. Throughfall (PI) for the season and successional stage (initial - INI, medium - MED and advanced - AVA ) in the Submontane Atlantic rain forest in Antonina, PR.

\section{$3.2 \mathrm{pH}$}

Os valores de $\mathrm{pH}$ na precipitação interna variaram entre 6,11 e 6,84, ficando mais próximos da neutralidade ( $\mathrm{pH}$ 7) nas estações de verão e outono (Figura 4). Pelo teste de Kruskal-Wallis, não foram observadas diferenças significativas entre os estágios vegetacionais (exceto no verão que ocorreu diferença entre o estágio avançado e médio), mas sim uma influência das estações do ano, com os menores valores de $\mathrm{pH}$ durante o período de inverno e primavera, e os maiores durante o verão e outono. Souza (2006) não observou efeito da estação do ano sobre os valores de $\mathrm{pH}$, mas este autor e Diniz et al. (2013) encontraram valores superiores de $\mathrm{pH}$ na precipitação interna em relação ao $\mathrm{pH}$ da precipitação externa.

Para Souza et al. (2007), a vegetação exerce função de controle das condições de pH da água, fazendo com que a faixa de $\mathrm{pH}$ varie menos na água interceptada em comparação a água precipitada fora da floresta. Ainda, segundo Diniz et al. (2013), os elementos presentes nas copas das árvores provavelmente possuem características alcalinas, fazendo com que dessa forma a água da chuva interceptada pela floresta apresente características mais alcalinas e mais constantes dentro da faixa de $\mathrm{pH}$. 


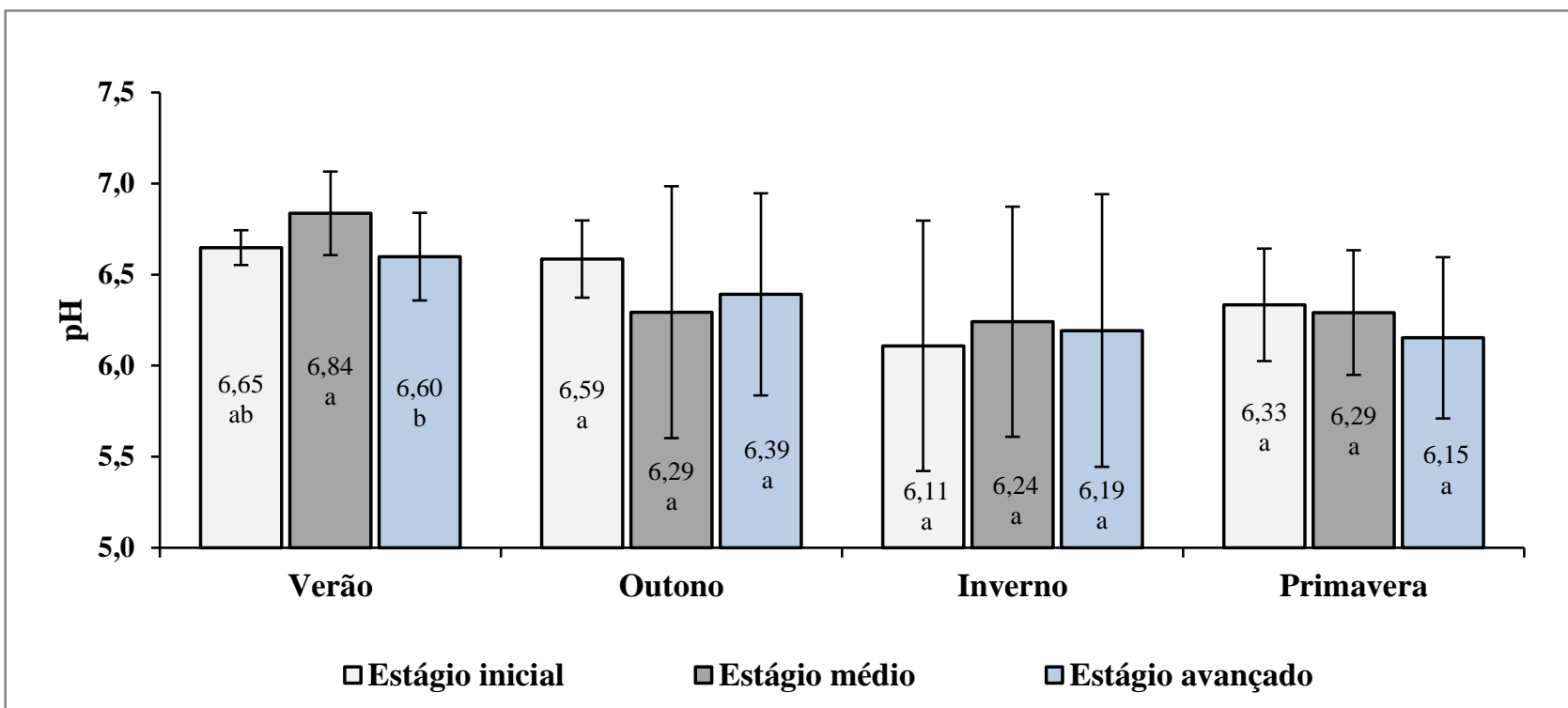

Figura 4. Comparação dos valores de pH na precipitação interna entre os estágios sucessionais e estações do ano em Floresta Ombrófila Densa Submontana em Antonina, PR. *Valores com mesma letra (para cada estação) não diferem estatisticamente entre si pelo teste de Kruskal-Wallis a $5 \%$ de probabilidade.

Figure 4. Comparison of $\mathrm{pH}$ values in the throughfall between successional stages and seasons in the Submontane Atlantic rain forest in Antonina, PR. *Values with the same letter (for each station) did not differ significantly by the Kruskal - Wallis test at $5 \%$ probability.

\subsection{CONCENTRAÇÃO E FLUXO DE NUTRIENTES NA PRECIPITAÇÃO INTERNA}

Os teores dos nutrientes nas soluções de precipitação interna mostraram variação com as estações do ano, sendo de maneira geral mais baixos nas estações com maiores precipitações (primavera e verão) e mais altos nas estações menos chuvosas (outono e inverno) (Figura 5). Esse padrão de sazonalidade caracteriza os efeitos de diluição e concentração dos elementos nas soluções de precipitação interna que também foi observado em outras pesquisas realizadas no litoral do Paraná (SOUZA, 2006; SCHEER, 2009). Souza et al. (2007) citam que a cobertura florestal influenciou também os valores dos parâmetros físicos da água de chuva, principalmente das chuvas, que ocorreram logo após um período de estiagem.

A identificação deste padrão de comportamento dos elementos nas soluções de precipitação interna sugere que os mesmos sejam principalmente de origem externa ao ecossistema (MARQUES; RANGER, 1997; SOUZA; MARQUES, 2010) e, particularmente no caso deste estudo, a principal fonte seria representada pelos aerossóis marinhos, dada a proximidade do oceano em relação às parcelas de estudo. Esse padrão de enriquecimento da 
precipitação interna por aerossóis marinhos pode determinar que quantidades significativas de nutrientes entrassem no sistema solo-planta, mesmo para nutrientes que costumam ser bastante lixiviados das folhas, como o K (DICKOW et al., 2009). Segundo Mengel e Kirkby (1982), o $\mathrm{K}$ é um dos nutrientes mais facilmente lixiviados das copas das árvores, por encontrar-se "livre", em forma solúvel, dentro da planta, não fazendo parte de nenhum composto orgânico. Diversos autores observaram que na solução lixiviada das folhas verdes e secas, o K foi o nutriente liberado em maiores quantidades (BRITEZ, 1994; MARQUES; RANGER, 1997; PINTO, 2001; SOUZA et al., 2007; DICKOW et al., 2009).
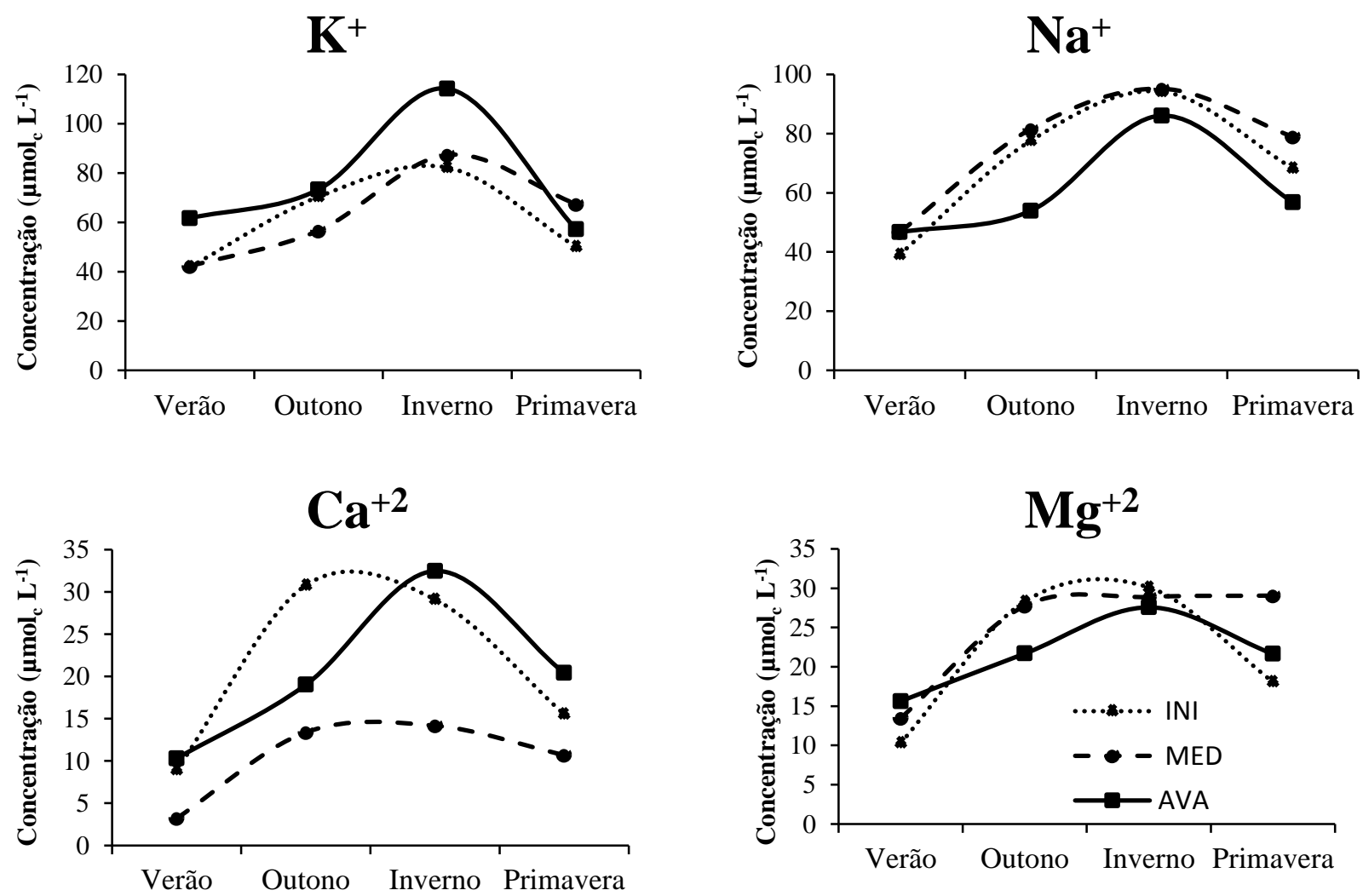

Figura 5. Concentração de $\mathrm{Ca}^{+2}, \mathrm{Mg}^{+2}, \mathrm{~K}^{+}$e $\mathrm{Na}^{+}$na solução de precipitação interna entre os estágios sucessionais (INI = inicial; MED = médio; AVA = avançado) e estações do ano, em Floresta Ombrófila Densa Submontana em Antonina, PR.

Figure 5. Concentration of $\mathrm{Ca}^{+2}, \mathrm{Mg}^{+2}, \mathrm{~K}^{+}$and $\mathrm{Na}^{+}$in the throughfall solution between successional stages (initial - INI , medium - MED and advanced - AVA ) and seasons, in the Submontane atlantic rain forest in Antonina, PR. 
Geralmente os elementos minerais $\mathrm{Ca}$ e $\mathrm{K}$ contidos na chuva podem ter origem continental, enquanto o $\mathrm{Na}$ e $\mathrm{Mg}$ podem ter origem marinha, no entanto, a concentração de nutrientes minerais, assim como os índices de pH da precipitação interna, são alterados em consequência da interação da água de precipitação com as espécies que compõem a floresta avaliada (BACKES, 2007). O fato da área deste estudo estar localizada em região costeira, explica a quantidade expressiva de sódio presente na solução precipitada. Lima (1985) salienta que a entrada de nutrientes pela precipitação e poeiras apresenta variação local e temporal, de acordo com a proximidade de fontes emissoras, e em relação à época do ano.

De modo geral, a fase avançada mostrou tendência de maiores teores para todos os elementos, exceto para o Na na primavera, cuja concentração presente na precipitação interna foi maior na fase sucessional média. Diniz et al. (2013) observou que a adição desses elementos ocorreu em maiores quantidades em áreas de fase sucessional avançada, seguida de média e inicial em Floresta Atlântica no Rio de Janeiro.

A ordem decrescente de concentração dos íons contidos na precipitação interna nas fases sucessionais foi: $\mathrm{K}^{+}>\mathrm{Na}^{+}>\mathrm{Ca}^{2+}>\mathrm{Mg}^{2+}$. Souza (2006) e Scheer (2009) encontraram ordem semelhante em áreas de Floresta Atlântica, apenas com valores maiores de $\mathrm{Na}$ em relação a K, explicada pela maior influência marinha das áreas de estudo dos autores citados.

O aporte (fluxo) de nutrientes seguiu a seguinte ordem decrescente $\mathrm{K}^{+}>\mathrm{Na}^{+}>\mathrm{Ca}^{+2}>\mathrm{Mg}^{+2}$, como também observado para os teores dos íons destes elementos nas soluções de precipitação interna (Tabela 1). Foram aportados entre 39 e $52 \mathrm{~kg} \mathrm{ha}^{-1} \mathrm{ano}^{-1}$ de K, entre 28 e $30 \mathrm{~kg} \mathrm{ha}^{-1}$ ano $^{-1}$ de $\mathrm{Na}$, entre 2 e $6 \mathrm{~kg} \mathrm{ha}^{-1}$ ano $^{-1}$ de Ca e entre 3 e $4 \mathrm{~kg} \mathrm{ha}^{-1} \mathrm{ano}^{-1}$ de Mg. A importância do aporte de nutrientes via precipitação interna em ecossistemas florestais, principalmente o $\mathrm{K}^{+}$, foi também ressaltado por Britez (1994), Schrumpf et al. (2006), Scheer (2009) e Diniz et al. (2013). Scheer (2009) encontrou 51,7 kg-1 $\mathrm{ha}^{-1} \mathrm{ano}^{-1} \mathrm{de} \mathrm{K}$ em área de Floresta Ombrófila Densa no Paraná. Já Diniz et al. (2013) encontrou valores de no máximo $9,8 \mathrm{~kg}^{-1} \mathrm{ha}^{-1}$ ano $^{-1}$ em fase sucessional avançada de Mata Atlântica na região do Rio de Janeiro. 
Tabela 1. Aporte de K, Na, Ca e $\mathrm{Mg}\left(\mathrm{kg} \mathrm{ha}^{-1}\right)$ da solução de precipitação interna por estágio sucessional (INI = inicial; MED = médio; AVA = avançado) e estação do ano em Floresta Ombrófila Densa Submontana, em Antonina, PR.

Table 1. Contribution of $\mathrm{K}, \mathrm{Na}, \mathrm{Ca}$ and $\mathrm{Mg}\left(\mathrm{kg} \mathrm{ha}^{-1}\right)$ of the internal precipitation solution by successional stage (initial - INI, medium - MED and advanced - AVA) and season in the Submontane atlantic rain forest in Antonina, PR.

\begin{tabular}{|c|c|c|c|c|c|c|c|c|c|c|}
\hline \multirow{3}{*}{ Nutriente } & \multirow{3}{*}{$\begin{array}{c}\begin{array}{c}\text { Estágio } \\
\text { sucessional }\end{array} \\
\text { INI }\end{array}$} & \multicolumn{8}{|c|}{ Estação do ano } & \multirow{3}{*}{ 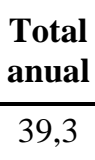 } \\
\hline & & \multicolumn{2}{|c|}{ Verão } & \multicolumn{2}{|c|}{ Outono } & \multicolumn{2}{|c|}{ Inverno } & \multicolumn{2}{|c|}{ Primavera } & \\
\hline & & 9,37 & $a b$ & 7,92 & $\mathrm{a}$ & 10,67 & $\mathrm{~b}$ & 11,34 & $\mathrm{a}$ & \\
\hline \multirow[t]{2}{*}{$\mathrm{K}^{+}$} & MED & 7,33 & $\mathrm{~b}$ & 7,82 & $\mathrm{a}$ & 10,82 & $\mathrm{~b}$ & 15,79 & $\mathrm{a}$ & 41,76 \\
\hline & AVA & 14,03 & $\mathrm{a}$ & 8,34 & $\mathrm{a}$ & 16,9 & $\mathrm{a}$ & 13,59 & $\mathrm{a}$ & 52,86 \\
\hline \multicolumn{2}{|c|}{ Média } & 10,24 & & $\mathbf{8 , 0 3}$ & & 12,80 & & 13,57 & $\mathbf{A}$ & 44,64 \\
\hline \multirow{3}{*}{$\mathrm{Na}^{+}$} & INI & 5,72 & $\mathrm{a}$ & 4,91 & $\mathrm{a}$ & 8,74 & $\mathrm{a}$ & 9,45 & $\mathrm{ab}$ & 28,82 \\
\hline & MED & 5,58 & $\mathrm{a}$ & 5,35 & $\mathrm{a}$ & 8,53 & $\mathrm{a}$ & 11,05 & $\mathrm{a}$ & 30,51 \\
\hline & AVA & 6,89 & $\mathrm{a}$ & 3,99 & $\mathrm{a}$ & 9 & $\mathrm{a}$ & 8,29 & $\mathrm{~b}$ & 28,18 \\
\hline \multicolumn{2}{|c|}{ Média } & 6,06 & & 4,75 & & 8,76 & & 9,60 & & 29,17 \\
\hline \multirow{3}{*}{$\mathrm{Ca}^{+2}$} & INI & 0,85 & $a b$ & 0,97 & $\mathrm{a}$ & 1,78 & $a b$ & 1,79 & $\mathrm{ab}$ & 5,4 \\
\hline & MED & 0,3 & $\mathrm{~b}$ & 0,35 & $\mathrm{~b}$ & 0,95 & $\mathrm{~b}$ & 1,06 & $\mathrm{~b}$ & 2,67 \\
\hline & AVA & 1,42 & $\mathrm{a}$ & 0,63 & $a b$ & 2,3 & $\mathrm{a}$ & 2,35 & $\mathrm{a}$ & 6,7 \\
\hline \multicolumn{2}{|c|}{ Média } & 0,86 & & 0,65 & & 1,68 & & 1,73 & & 4,92 \\
\hline \multirow{3}{*}{$\mathrm{Mg}^{+2}$} & INI & 0,65 & $\mathrm{a}$ & 0,78 & $\mathrm{a}$ & 1,24 & $\mathrm{a}$ & 1,17 & $\mathrm{a}$ & 3,85 \\
\hline & MED & 0,65 & $\mathrm{a}$ & 1,03 & $\mathrm{a}$ & 1,12 & $\mathrm{a}$ & 1,95 & $\mathrm{a}$ & 4,76 \\
\hline & AVA & 1,19 & $\mathrm{a}$ & 0,74 & $\mathrm{a}$ & 1,29 & $\mathrm{a}$ & 1,44 & $\mathrm{a}$ & 4,67 \\
\hline \multicolumn{2}{|c|}{ Média } & $\mathbf{0 , 8 3}$ & & $\mathbf{0 , 8 5}$ & & 1,22 & & 1,52 & & 4,43 \\
\hline
\end{tabular}

*Valores em coluna com mesma letra (para todos os nutrientes) não diferem estatisticamente entre si pelo teste de comparações múltiplas de Kruskal-Wallis a $5 \%$ de probabilidade

Foi identificada uma tendência de aumento do fluxo total de $\mathrm{K}^{+}$com o avanço da fase sucessional. O fluxo de $\mathrm{Ca}^{+2}$ foi maior no estágio avançado, seguido pelos estágios inicial e médio. Para o $\mathrm{Na}^{+}$e $\mathrm{Mg}^{2+}$ ocorreu um aporte ligeiramente superior no estágio médio. Souza e Marques (2010) e Diniz et al. (2013) relataram que a tendência de aumento da adição de nutrientes pela precipitação interna acompanhou o grau de regeneração florestal.

Considerando as estações do ano, de maneira geral, os aportes seguiram a seguinte ordem: primavera > inverno > verão > outono. Ou seja, os fluxos de nutrientes não se explicam apenas pela quantidade de precipitação ou pela concentração dos nutrientes nas soluções. $\mathrm{Na}$ primavera, os elevados valores de precipitação (Figura 3) e valores intermediários de concentração (Figura 5) resultaram nos maiores fluxos observados. No inverno, a elevada concentração compensou a baixa precipitação; no verão, valores intermediários de precipitação compensaram os baixos valores de concentração; e no outono, a baixa precipitação foi 
insuficiente para garantir fluxos mais elevados. É interessante lembrar que o outono vem logo depois do verão, período de intensas chuvas nesta região, quando boa parte dos elementos depositados sobre a cobertura florestal já foram lavados e transferidos para o solo florestal, o que explica a baixa contribuição desta estação para o aporte de nutrientes.

\section{CONCLUSÕES}

Os valores de $\mathrm{pH}$ e a concentração dos nutrientes $\left(\mathrm{Ca}^{2+}, \mathrm{Mg}^{2+}, \mathrm{K}^{+}\right.$e $\left.\mathrm{Na}^{+}\right)$em solução sofrem influência da quantidade de precipitação, a qual está vinculada às estações do ano. Esta influência se traduz por um efeito de concentração/diluição, que eleva a concentração de íons nas estações mais secas e diminui esta concentração nas estações mais úmidas. Não foi identificado efeito claro da fase sucessional sobre a concentração de íons e sobre o pH das soluções de precipitação interna.

O aporte de nutrientes via precipitação interna foi superior no inverno (estação mais seca e com elevada concentração de nutrientes) e na primavera (estação mais úmida e com concentrações intermediárias de nutrientes), mostrando-se influenciado tanto pela quantidade de precipitação quanto pela concentração dos nutrientes em solução.

As quantidades de nutrientes que chegam ao solo florestal via precipitação interna, sobretudo K, indicam esta via como um processo importante na transferência de nutrientes minerais para o solo florestal.

\section{REFERÊNCIAS}

ARCOVA, F. C. S.; CICCO, V. Fluxo de nutrientes através da precipitação, precipitação interna e escoamento pelo tronco em floresta natural secundária no Parque Estadual da Serra do Mar Núcleo Cunha - SP. Boletim Técnico do I.F., São Paulo, v. 41, n. 1, p. 37-58, 1987.

ARCOVA, F. C. S.; CICCO, V. DE; ROCHA, P. A. B. Precipitação efetiva e interceptação das chuvas por floresta de Mata Atlântica em uma microbacia experimental em Cunha - São Paulo. Revista Árvore, v. 27, n. 2, p. 257-262, 2003.

BACKES, A. Precipitação pluviométrica e concentração de nutrientes minerais na água de chuva na região da floresta nacional de São Francisco de Paula, Rio Grande do Sul, Brasil. Pesquisas Botânicas, n. 58, p. 331-346, 2007. 
BIANCHIN, J. E. Aporte de fitomassa e nutrientes em florestas secundárias da Mata Atlântica no litoral do Paraná, 2013. 102p. Dissertação (Mestrado em Engenharia Florestal) - Universidade Federal do Paraná, Curitiba, PR.

BRITEZ, R. M. Ciclagem de nutrientes minerais em duas florestas da planície litorânea da Ilha do Mel, Paranaguá, PR. 1994. 240 f. Dissertação (Mestrado em Ciências do Solo) Universidade Federal do Paraná, Curitiba, PR.

CINTRA, A. T. F. Entradas atmosféricas de nutrientes e poluentes em um ecossistema florestal urbano, Maciço da Pedra Branca - RJ. 133 f. Dissertação (Programa de PósGraduação em Química) - Pontifíca Universidade Católica do RJ, Rio de Janeiro, 2004.

DICKOW, K. M. C., MARQUES, R., PINTO, C. B. Lixiviação de nutrientes da serapilheira recém-depositada em sucessão ecológica na Floresta Atlântica, Litoral do Paraná. Revista Floresta, v. 39, n. 1, p. 145-156, 2009.

DICKOW, K. M. C.; MARQUES, R.; PINTO, C. B.; HOFER, H. Produção de serapilheira em diferentes fases sucessionais de uma floresta subtropical secundária, em Antonina, PR. Cerne, v. 18, n. 1, p. 75-86, 2012.

DINIZ, A.R.; PEREIRA, M.G.; BALIEIRO, F.C.; MACHADO, D.L.; MENEZES, C.E.G. Precipitação e aporte de nutrientes em diferentes estádios sucessionais de Floresta Atlântica, Pinheiral-RJ. Ciência Florestal, v. 23, n.3, p. 389-399, 2013.

EQUIPE ESTATCAMP. Software Action. São Carlos: ESTATCAMP, 2014. Disponível em: $<$ http://www.portalaction.combr/>.

FORTI, M. C.; BICUDO, D. C. BOUROTTE, C.; CICCO, V.; ARCOVA, F. C. S. Rainfall and throughfall chemistry in the Atlantic Forest: a comparison between urban and natural areas (São Paulo State, Brazil). Hydrology and Earth System Sciences, v. 9, n. 6, p. 570-585, 2005.

GOLlEY, F.B.; MCGINNIS, J. T.; CLEMENTS, R. G.; CHILD, G. I.; DUEVER, M. J. Ciclagem de minerais em um ecossistema de floresta tropical úmida. São Paulo: EPU/EDUSP; 1978.

HAAG, P. H. Ciclagem de nutrientes em florestas tropicais. Fundação Cargil, Campinas, $1985,144 p$.

IBGE. FUNDAÇÃO INSTITUTO BRASILEIRO DE GEOGRAFIA E ESTATÍSTICA. Manual Técnico da Vegetação Brasileira. Rio de Janeiro, 2 ed. 2012, 271 p.

LIEBSCH, D.; GOLDENBERG, R.; MARQUES, M. C. M. Florística e estrutura de comunidades vegetais em uma cronosequência de Floresta Atlântica no Estado do Paraná, Brasil. Acta Botanica Brasilica, v. 21, n. 4, p. 983-992, 2007. 
LIMA, W. P. Estudos de alguns aspectos quantitativos e qualitativos do balanço em plantações de eucaliptos e pinus. 1975. 111f. Tese (Doutorado em Ciência Florestal) -Escola Superior de Agricultura "Luiz de Queiroz", Piracicaba, 1975.

LIMA, W. P. Ação das chuvas no ciclo biogeoquímico de nutrientes em plantações de pinheiros tropicais em Cerradão. IPEF, n. 30, p. 13-17, 1985.

LORENZON, A. S.; DIAS, H. C. T.; LEITE, H. G. Precipitação efetiva e interceptação da chuva em um fragmento florestal com diferentes estágios de regeneração. Revista Árvore, v. 37, n. 4, p. 619-627, 2013.

MAACK, R. Geografia física do Estado do Paraná. 3.ed. Curitiba: Imprensa Oficial, 2002.

MARQUES, R.; RANGER, J. Nutrient dynamics in a chronosequence of Douglas-fir (Pseudotsuga menziesii (Mirb.) Franco) stands on the Beaujolais Mounts (France). 1: Qualitative approach. Forest Ecology and Management, v. 91, n.2-3, p. 255-277, 1997.

MARQUES, R.; RANGER, J.; VILLETTE, S.; GRANIER, A. Nutrient dynamics in a chronosequence of Douglas-fir (Pseudotsuga menziesii (Mirb.) Franco) stands on the Beaujolais Mounts (France). 2: Quantitative approach. Forest Ecology and Management, v. 92, n.2-3, p. 167-197, 1997.

MARSCHNER, H. Mineral nutrition of higher plants. London: Academic Press Limited, 1986. p.112-114.

MENGEL, K.; KIRKBY, E. E. Principles of plant nutrition. 3.ed. Berna: IPI, 1982. 562 p.

MILLER, H.G. Dynamic of nutrient cycling in plantations ecosystems. Nutrition of plantation forest. London: Academic, 1984. p. 53-78.

MINEROPAR. Atlas Geológico do Estado do Paraná. Curitiba: MINEROPAR, 116 p. 2001.

MORAES, R. M. Ciclagem de nutrientes minerais em mata atlântica de encosta e mata sobre restinga, na ilha do Cardoso, Cananéia, SP: produção de serapilheira e transferência de nutrientes. 1993. 151 p. Dissertação (Mestrado em Ecologia Geral) Universidade de São Paulo, São Paulo.

PINTO, C. B. Contribuição de espécies arbóreas para a ciclagem de nutrientes em sucessão vegetal na Floresta Ombrófila Densa das Terras Baixas. 2001. 80p. Dissertação (Mestrado em Engenharia Florestal) - Universidade Federal do Paraná, Curitiba, PR.

PINTO, C. B.; MARQUES, R. Aporte de nutrientes por frações da serapilheira em sucessão ecológica de um ecossistema da Floresta Atlântica. Revista Floresta, v. 33, n. 3, p. 257-264, 2003. 
PROTIL, C. Z. Contribuição de quatro espécies arbóreas ao ciclo biogeoquímico em Floresta Atlântica na planície litorânea do Paraná. 2006. 127 f. Tese (Doutorado em Engenharia Florestal) - Universidade Federal do Paraná, Curitiba, PR.

SCHEER, M. B. Fluxo de nutrientes pela precipitação pluviométrica em dois trechos de Floresta Ombrófila Densa em Guaraqueçaba, Paraná. Floresta, v. 39, n. 1, p. 117-130, 2009.

SCHRUMPF, M.; ZECH, W.; AXMACHER, J.C.; LYARUU, H.V. Biogeochemistry of an afrotropical montane rain forest on Mt. Kilimanjaro, Tanzania. Journal of Tropical Ecology, v. 22, n. 01, p. 77-89, 2006.

SIMEPAR. Dados Históricos, 1999 à 2015 - Estação: Antônina - PR. Disponível em: <http://www.simepar.br>. Antonina, PR. 2015.

SOUZA, A. S.; MELLO, W. Z.; MALDONADO, J.; EVANGELISTA, H. Composição química da chuva e aporte atmosférico na Ilha Grande, RJ. Química Nova, v. 29, n. 3, p. 471476, 2006.

SOUZA, L.C. Dinâmica de nutrientes na precipitação, em solução de solo e lençol freático em três tipologias florestais sobre Espodossolo, no litoral do Paraná. 2006. Tese (Doutorado em Engenharia Florestal) - Universidade Federal do Paraná, Curitiba, PR.

SOUZA, L. C.; MARQUES, R. Fluxo De Nutrientes Em Floresta Ombrófila Densa Das Terras Baixas No Litoral Do Paraná. Revista Floresta, v. 40, n. 1, p. 125-136, 2010.

SOUZA, V. V.; DIAS, H. C. T.; COSTA, A. A.; OLIVEIRA JUNIOR, J. C. Análise da qualidade das águas das precipitações em aberto e efetiva em um fragmento secundário da Mata Atlântica, no Município de Viçosa - MG. Revista Árvore, v. 31, n. 4, p. 737-743, 2007.

WOICIECHOWSKI, T. Ciclagem de fitomassa e nutrientes na Floresta Ombrófila Densa Submontana no litoral do Paraná. 2015. Tese (Doutorado em Engenharia Florestal) Universidade Federal do Paraná, Curitiba, PR.

\section{AGRADECIMENTOS}

Ao SIMEPAR, pelo fornecimento de dados climáticos utilizados neste estudo. 